\title{
A Cultura Política De 68: Reflexões Sobre A Resistência Estudantil Em Brasil E Portugal
}

\author{
Pablo Almada $^{1}$
}

\begin{abstract}
Resumo
Os movimentos estudantis foram consideráveis protagonistas de ações coletivas nos anos 1960, com destaque aos eventos do Maio de 1968. Nesse artigo procura-se repensar 1968 em sua cultura política, que, embora assentada em diversas disjunturas sociais, resulta numa compreensão alargada e descentralizada. Será realizada uma revisão das mobilizações estudantis contra os regimes ditatoriais do Brasil e ao final do Estado Novo em Portugal, no sentido de perceber as dinâmicas de repressão utilizadas para a contenção desses protestos. Em ambos os países, as mobilizações estudantis se distinguiram dos países centrais, seja por suas reivindicações, seja por terem sido permeadas por relações de violência direta ou de violência simbólica. Por fim, entende-se que a resistência estudantil ofereceu elementos de ampliação da cultura política para as duas transições democráticas.
\end{abstract}

Palavras-Chave: Movimento estudantil. Ação coletiva. Resistência. Autoritarismo. Violência.

\section{The Political Culture of 68: Reflections on Student's Resistance in Brazil and Portugal}

\begin{abstract}
The students' movements were protagonists of collective actions in the 1960s, with emphasis on the May 1968 events. This article seeks to rethink 1968's political culture which was founded upon various social disjunctures and resulted in an extended

1 Doutor em Democracia no Século XXI pela Universidde de Coimbra, Portugal. Professor do Departamento de Ciências Sociais, área de Sociologia, da Universidade Estadual de Londrina (UEL), Brasil. pabloera@gmail.com
\end{abstract}


and decentralized understanding of politics. A review will be held on the students' protests against the Brazilian Military Dicatorship and at the end of Estado Novo in Portugal in order to understand the dynamics of repression used to contain these protests. In both countries, the student's mobilizations were distinguished from the ones that took place in central countries, either by their claims, either because they were permeated by relations of direct violence or symbolic violence. Finally, it is understood that the student's resistance provided elements for an expansion of political culture which was crucial for both democratic transitions.

Keywords: Students movements. Collective action. Resistance. Authoritarianism. Violence.

\section{INTRODUÇÃo}

As abordagens sobre as ações coletivas estudantis das décadas de 1960 e 1970 constituíram-se, passados quase 50 anos do Maio de 1968, um enorme campo de reflexão interdisciplinar. Despertaram olhares retrospectivos, saudosistas, ressentidos, de vitória ou de derrota, de continuidades e rupturas: significados ainda disputados nas gerações posteriores. Essa quantidade de significações conduziram a indagações que demarcam os limites práticos e conceituais das revoltas estudantis.

Embora possa-se identificar o período através da rebelião dos estudantes e trabalhadores franceses, destacou-se a ocorrência global de greves e protestos realizados em fábricas e universidades. Nessa seara, os estudos comparados existentes convergem para os ocorridos nos países centrais (França, Alemanha e Estados Unidos), com referências marginais às dinâmicas de protestos nos países do Sul global. Atentando para essa lacuna, pretende-se aqui observar o contexto de Brasil e Portugal, à luz das formulações teórico-analíticas que elencaram os protestos estudantis do Maio de 1968 como objeto de estudo.

Dessa forma, se as experiências do Maio de 1968 tomadas como paradigma são as experiências dos países centrais, isso ocorre porque há uma razão metonímica, ou seja, um esquema de classificação 
de simetrias e hierarquias que tanto obscurece um dos "lados", tornando-o assimétrico e inferiorizado àquele lado visível (SANTOS, 2006, p. 94). A possibilidade metodológica de crítica desse modelo de razão reside na ruptura com as dicotomias e relações de poder vigentes, vislumbrando relações alternativas que ofuscam a construção hegemônica de poder no conhecimento produzido.

Assim sendo, o presente artigo procurará apresentar alguns dos resultados da pesquisa de doutorado "A Árvore de Maio: Resistência estudantil e sua atualidade (Brasil e Portugal)", elaborado no Centro de Estudos Sociais da Universidade de Coimbra ${ }^{2}$. Dessa forma, são elencadas duas tarefas. Primeiramente, repensar o marco de ações coletivas do Maio de 1968, alargando seu significado como um movimento global e anti-sistêmico, cujo resultado é a crítica ao modelo educacional è à atitude política autoritária. Em seguida, é dada uma breve releitura histórica dos manifestos estudantis de 1968 nos contextos autoritários de Brasil e Portugal, com objetivo de encontrar nuances aproximativas. Assim, procura-se elucidar as diferenças com relação aos países centrais democráticos, que se dão na recusa de modelos de reforma universitária tecnocrática e apontando para a efetivação da democracia de base.

\section{Repensando o Maio de 1968}

O que aqui será entendido como o Maio de 1968 não diz apenas ao evento parisiense, tampouco, às manifestações estudantis restritas ao mês e ao ano supracitado. O Maio de 1968 tratou-se muito mais de um período de efervescência social e política global que criou efeitos de disjunturas nas culturas políticas locais, nacionais e globais, criticando as mudanças técnico-produtivas e de mercado que se iniciam nos países centrais e se expandem aos países em condições

2 Financiamento realizado pela Fundação para a Ciência e a Tecnologia (FCT) de Portugal, durante os anos de 2009 e 2013. 
semi-periférica e periférica, permitindo o surgimento de inúmeros protestos de resistência. Por isso, são compreendidos como movimentos anti-sistêmicos (ARRIGHI, HOPKINS; WALLERSTEIN, 1989), cuja referência é o sistema-mundo do capitalismo histórico, que se relaciona em termos de classes sociais e grupos de status (juventude, gênero, etnicidade, etc.), abrindo uma janela para novas disputas de poder.

O Maio de 1968 apontou para a dimensão anti-sistêmica por sua condição de movimento global, que efetivou um processo de elaboração de uma nova cultura política. Não se trata simplesmente de enfatizar a emergência dos "novos sujeitos" revolucionários em detrimento dos antigos sujeitos políticos, nem tampouco, considerar o abandono de reivindicações materiais e o desprendimento da condição classista para assumir uma forma de reivindicação imaterial, de construção de novos movimentos sociais focados nas relações identitárias ou de evidências de um princípio político normativo embasado na razão comunicativa e na efetividade técnica da política em detrimento de suas nuances ideológicas (HABERMAS, 1971; TOURAINE, 1971). A nova cultura política está presente quando esses sujeitos, que não se encontravam satisfeitos com as condições materiais dadas pelo capitalismo e pelas promessas do modelo de Estado de Bem Estar Social, utilizam-se, primeiramente, de sua condição classista para, a partir dela, agregar reivindicações em torno do aprofundamento democrático necessário. Embora essa aproximação tenha sido crucial para a realização dos protestos, eles somente alcançaram amplitude conforme evidenciaram a crítica da exploração e do racionalismo do capitalismo do pós-guerra, o que permitiu, do ponto de vista dos caminhos prático-políticos da conjuntura, a gestação de diversidades e opções de ação, que se confundem ou se redefinem, contrárias às práticas de dominação vigentes. Isso não significou a identificação imediata da crítica ao capitalismo com o alinhamento ao socialismo soviético, assim como dado na dicotomia institucional da Guerra Fria. 
O núcleo da segunda dimensão anti-sistêmica reside na aproximação, pelo menos restrita ao imaginário, dos movimentos estudantis com os movimentos anti-guerra e com os movimentos de libertação nacional do "Terceiro Mundo", como as Revoluções Cubana e Chinesa, formando um espaço de florescência da New Left nos países centrais. Assim, ao invés desses movimentos serem reduzidos às dinâmicas dos

[...] "novos movimentos sociais", costumeiramente analisados em termos de nação, raça, gênero e formas de organização, mas ausente de suas interconexões, a construção desse imaginário permite "universalizar nosso entendimento da subjetividade desses movimentos dentro dos marcos objetivos das forças em jogo no sistema mundo" (KATSIAFICAS, 1987, p. 14).

De forma específica, há uma imensa gama de percepções que demarcam o Maio de 1968 e suas respectivas disjunturas. A primeira está na relação classista desses protestos. Se, por um lado, demarca-se a prática política individualista pequeno-burguesa, suposta na desilusão de alcançar posições privilegiadas nos processos de mobilidade social (FORACCHI, 1969), por outro, entende-se que as classes médias estariam emergindo como novos atores, das quais proveriam reivindicações culturais, identitárias e de acesso a privilégios, que poderiam ser garantidos ou não - mediante mérito individual e oportunidades de promoção, como as oportunidades educacionais pelo Estado (BOLTANSKI; CHIAPELLO, 1999; CHAUVEL, 2002). A segunda disjuntura está presente nas análises que interpretaram as revoltas estudantis como uma batalha intergeracional que demarcou uma revolta edipiana dos filhos contra seus pais (BARKER, 2008; BOREN, 2001) e aquelas que, negando o caráter a-histórico das primeiras e se perguntando o motivo da especificidade das manifestações terem ocorrido em 1968 e não outrora, trouxeram à luz a composição social da juventude nesses protestos, seja pela revitalização do imaginário político ou na composição de uma fração de classe social (MARCUSE, 
1973). A terceira e última disjuntura remete-se à questão dos tempos históricos e suas expressões culturais, pois referencia-se na percepção de uma periodização dos anos 1960, com o fim de um período marcado por acontecimentos globais, pelo surgimento da contracultura e pelo entendimento de que os protestos de jovens e estudante contrapuseram-se ao poder disciplinar excessivo das sociedades de controle (JAMESON, 1992; MARWICK, 1998; STEPHENS, 1998).

As três disjunturas podem ser sintetizadas na compreensão de revolução cultural (MARCUSE, 2005, p. 18), conforme expressamse demandas políticas e econômicas articuladas com sua respectiva dimensão subjetiva, de floração de desejos para libertação dos sentidos. A abertura do "poder para a imaginação", que irá ressoar efeitos nas novas esquerdas contra as experiências de realidade reprimida e o slogan de 1968, "seja realista, peça o impossível", são mostras que a revolução cultural corroborou para o revitalizar das experiências revolucionárias. Há, nesse sentido, uma perspectiva emancipatória enredada de engajamento político para a superação das mazelas causadas pelo capitalismo, interligada ao autoritarismo político dos governos. Por isso, articulou-se a crítica artística - que entendia o capitalismo como fonte de opressão à liberdade e à autonomia gerando desencantamento - com a crítica social - que entendia o capitalismo como fonte de misérias, desigualdade, oportunismo e egoísmo, causando destruição de laços sociais (BOLTANSKI; CHIAPELLO, 1999). Assim sendo, a violência foi o elemento de mediação entre as instituições políticas autoritárias e as demandas dos protestos, já que estariam assegurados os moldes de opressão, da legitimação do Estado e das desigualdades sociais, afastando os obstáculos e as propostas alternativas para uma sociedade mais igualitária. 


\section{Da Reforma Universitária À Contestação Da Ditadura}

Operíodo da ditadura militar brasileira (1964-1985) apresentou um amplo processo de transformações, associadas aos conflitos entre os governos militares e os setores de oposição que, a partir da suspensão democrática, resultaram no uso exacerbado da violência e em infrações de direitos humanos. A tomada do governo pelos militares foi, entre outros fatores, uma reação prévia às organizações do movimento popular por reformas de base, que ganhavam força no governo de João Goulart. Com a organização de setores conservadores da Igreja Católica e da classe média, como nas duas “Marchas da Família com Deus pela Liberdade", surgiram argumentos para legitimar a intervenção militar e frear as reformas sociais. As oposições entre as classes dominantes e o restante da população se acirrou, aumentaram as greves operárias e, da mesma forma, aumentava o controle do capital estrangeiro em setores industriais, possibilitando a confluência entre setores conservadores e setores capitalistas (MARINI, 2000).

Os grupos de oposição (setores das classes trabalhadoras urbanas e rurais, profissionais liberais, estudantes, entre outros) promoveram manifestações de resistência ao longo dos 25 anos de regime. Inicialmente, parte da oposição era composta pelo Partido Comunista do Brasil (PCB), que continha raízes orgânicas nos meios populares e operários, além de intelectuais não-orgânicos mas de intervenção militante. As formulações teóricas do PCB e suas cisões permitiram visões diferenciadas do partido em seu interior, em torno de três fundamentos: o caráter da revolução brasileira, o tipo de organização revolucionária e as formas de luta para se chegar ao poder (RIDENTI, 2010). A direção central do PCB entendia que a revolução brasileira deveria ser programada com duas etapas: a etapaburguesa, que superaria os entraves feudais na economia nacional e sua subordinação ao imperialismo norte-americano; e a etapa democrática, constituída de 
um governo popular. Essa separação permitiu aproximações maoístas e foquistas-cubanas, que defendiam a revisão das etapas da revolução, seu caráter e a prática "revolucionária", tanto pela luta armada como pela mobilização pacífica (GORENDER, 1987; REIS FILHO, 1990).

No movimento estudantil, a ressonância dessa divisão efetivou um processo de concorrência interna na entidade. Apesar da União Nacional dos Estudantes (UNE) ser conduzida pelo grupo da Igreja Católica progressista, a Ação Popular (AP), correntes de esquerda disputavam as organizações de base e a hegemonia nas universidades (MARTINS FILHO, 1987; POERNER, 2008). A organização estudantil obteve avanços perante as políticas militares direcionadas à universidade, sobretudo, quanto às reformas universitárias.

Iniciadas em 1964, com a Lei $n^{\underline{0}} 4.464$ (Lei Suplicy), almejavase impedir o exercício da representação estudantil, suspender as atividades da UNE e criar representações estudantis atreladas ao Estado. Da aproximação entre o Ministério da Educação (MEC) e a United States Agency for International Development (USAID) resultariam reformas em todos os segmentos do ensino brasileiro, no sentido de "modernização" aos moldes das escolas e universidades norte-americanas: abria-se a perspectiva de suspensão do ensino público e gratuito e das influências dos estudantes nos destinos da universidade. Em suma, entende-se que a reforma representava $a$ submissão da universidade a uma tutela exterior, a negação do radicalismo intelectual e a oposição ao fortalecimento das aspirações dos jovens pela reconstrução da sociedade (FERNANDES, 1975). A UNE obteve significativa participação na mobilização contra a reforma universitária, através de experiências de politização que colocavam em causa o tecnicismo modernizante das reformas desejadas pelos militares.

As lutas estudantis de 1968 foram demarcadas por episódios pontuais em situações de tensão com as forças policiais (VALLE, 2008). A morte do estudante Edson Luiz de Lima Souto, em 28 de 
março, no Restaurante do Calabouço da Universidade Federal do Rio de Janeiro (UFRJ) é o primeiro e emblemático caso. Ele pode ser compreendido num contexto imediato de fortalecimento da participação dos estudantes no interior das universidades. Aquelas manifestações, organizadas pela Força Unida dos Estudantes do Calabouço (FUEC), criticava as precárias condições do restaurante e o aumento do valor das refeições. Durante uma assembleia estudantil, o batalhão de choque da Polícia Militar invadiu o restaurante e fez disparos de metralhadora, matando o estudante de 16 anos. Com esse fatídico episódio, se seguiram várias manifestações de solidariedade, conduzidas por centros acadêmicos e diretórios.

Em 21 de junho, ainda no Rio, foram marcados protestos contra a reforma universitária e contra a repressão policial, em frente ao prédio do MEC e da Embaixada dos EUA. Sucederam-se mais conflitos com a polícia, que usou de gás lacrimogêneo para dispersar os manifestantes. Estes foram cercados por agentes do DOPS, da Polícia Federal e da PM, que atirou sobre eles. O episódio, conhecido como Sexta Feira Sangrenta, resultou em duas mortes e mais um ferido (que faleceu dias depois), além de um policial morto a tijoladas. Naquele momento, Vladimir Palmeira, Presidente da União Metropolitana de Estudantes (UME-RJ) e membro da Dissidência Guanabara (DI-GB), foi detido e enquadrado, junto com outros manifestantes, pela Lei de Segurança Nacional.

Tão logo a truculência policial começava a ser uma marca presente para reprimir as manifestações, outros setores da sociedade acabaram por apoiá-las. Na Passeata dos Cem Mil, de 26 de junho, no Rio, foram às ruas estudantes, intelectuais, artistas, professores, jornalistas e populares, reivindicando o fim das ações policiais e a libertação dos presos políticos. A passeata foi de cunho pacífico, não registrou conflitos com a polícia, mas foi essencial para aprofundar as divisões no seio da esquerda. Por um lado, defensores da luta 
armada, por outro, defensores da luta pacífica, e, ainda, defensores da organização política vanguardista e defensores da militância de base. Os setores repressivos do Estado focaram as lideranças estudantis, com objetivo de combatê-las na lógica do "inimigo interno", operando um direcionamento da repressão.

Na Rua Maria Antônia, em São Paulo, no dia 03 de outubro, efetivava-se um acirramento de posições ideologizadas, protagonizado pelos estudantes da Universidade de São Paulo (Filo-USP), ligados a UNE, juntamente com secundaristas da União Brasileira de Estudantes Secundaristas (UBES) e, em oposição, os estudantes da Universidade Presbiteriana Mackenzie, ligados ao Comando de Caça aos Comunistas (CCC). Os estudantes da USP faziam um pedágio para arrecadarem fundos para o Congresso da UNE e foram surpreendidos pelos estudantes do Mackenzie que atiraram pedras e ácidos contra os primeiros, que contra-atacaram. No confronto, que durou cerca de quatro horas, guardas civis entraram no Mackenzie e tentaram conter o CCC, mas estudantes da UNE e UBES, liderados por José Dirceu, invadiram o prédio, escrevendo nas paredes palavras de ordem contra o CCC. No dia seguinte, ocorreu um tiroteio e o prédio da Filo-USP ficou praticamente destruído ao ser incendiado por bombas. No confronto, um estudante foi morto e vários outros presos. Após o ocorrido, os estudantes da USP iniciaram um protesto percorrendo o centro de São Paulo. Entretanto, na sequência, o movimento se enfraqueceu, reduziram-se os participantes e as atividades políticas, facilitando a diluição das passeatas e aprofundando os rachas internos.

Na ocasião da realização do XXXํo Congresso daUNE, militantes de vários estados foram mobilizados para realização de encontros prévios e, embora alguns encontros tenham sido desestruturados pela polícia, o congresso foi realizado. Em Ibiúna-SP, as atividades se iniciaram em 10 de outubro, com previsão para cinco dias de evento. A interrupção foi abrupta no terceiro dia, quando a polícia invadiu o local 
e prendeu cerca de mil estudantes em uma grande operação montada pelo DOPS de São Paulo. A interrupção do XXXํㅡㅁ Congresso foi um marco histórico para o movimento estudantil e para a continuidade da UNE. Após a prisão, os estudantes foram conduzidos a seus estados de origem, mas os líderes políticos - José Dirceu, Vladmir Palmeira e Luís Travassos - continuaram presos. Após esse ocorrido, a UNE foi colocada na ilegalidade e somente voltaria à atividade nos anos 1980, restringindo a atividade política dos estudantes ${ }^{3}$.

A ameaça de ruptura política institucional, aberta pela contestação estudantil fez o governo militar avançar medidas de cunho repressivo, como o Ato Institucional № 5. Nele inscrevia-se a contenção das lutas sociais, dada pela suspensão da garantia de habeas corpus na infração da Lei de Segurança Nacional, bem como a suspensão dos direitos políticos dos cidadãos e na autorização do Estado de Sítio. Um novo marco legal da reforma universitária foi aprovado no final de 1968 (Lei no 5.540/68), e, no inicio de 1969, foi aprovado o Decreto-Lei 477, que almejou maior controle das estruturas administrativas das universidades e das atividades políticas estudantis. Perante a situação de tensão garantida pelo AI-5 e pela suspensão da representatividade estudantil, muitos estudantes e dirigentes optaram pela clandestinidade e pela militância nas organizações de esquerda. Sob forte perseguição política, alguns remanescentes da UNE ainda buscaram eleger a diretoria da entidade, mas sofreram com a violência institucionalizada que criou mais vítimas e desaparecidos políticos.

A partir desse panorama, entende-se que as revoltas estudantis de 1968 estiveram relacionadas com duas dimensões: a primeira, político-educacional, conforme o estopim de reforma universitária permite a organização interna estudantil; a segunda,

3 Jean Marc von der Weld (Projeto Memória do Movimento Estudantil, Entrevista a Jean Marc von der Weid, realizada por Carla Siqueira e Ana Paula Goulart em 07/10/2004) aponta para tentativa de organização política realizada pela Ação Popular, após a prisão dos estudantes no Congresso da Une, algo que resultou sem sucesso. 
político-institucional, conforme a ação repressiva toma corpo da relação entre governo e estudantes. Uma não é redutível a outra, embora, a dimensão política institucional tenha uma abrangência maior que a primeira. Em ambas estão presentes os limites do projeto modernizante da Ditadura Militar, que adotaria uma postura tecnocrática que subjugaria a atividade política democrática estudantil. Nos anos 1970, a reorganização estudantil passou pelas experiências de repolitização do espaço acadêmico, o que não trouxe conflitos imediatos, mas a sensação de silenciamento do movimento estudantil, que estaria voltado para a dimensão político-educacional. Esse ciclo volta a ter um período político-institucional a partir de 1977, quando se inicia um amplo processo de reorganização institucional da UNE conjuntamente com a retomada das lutas sociais de vários setores de trabalhadores urbanos, rurais, de movimentos liderados pelas alas progressistas da Igreja Católica, de movimentos sociais urbanos e rurais, revitalização do sindicalismo e luta pela anistia dos presos políticos e pela democratização do país.

\section{Das Liberdades Acadêmicas À Intervenção Estudantil}

O Estado Novo português (1933-1974), nascido dos desdobramentos autoritários dos anos 1930 na Europa, enfrentava momentos de crise na década de 1960 por conta de aspectos econômicos, políticos e sociais. A via econômico-política seguida pautava-se pela intervenção do Estado na economia, com incentivos aos setores agrário-coloniais e com escassos investimentos nas indústrias (PEREIRA, 1979). O forte controle sobre os movimentos operários e campesinos compunha o modelo de estado corporativista, assentado sobre um profundo conservadorismo aliado a setores das elites e da Igreja Católica. Esses desdobramentos asseguram o exercício de um poder político de cunho fascista diferenciado, o chamado "fascismo 
a portuguesa", organizado em torno das características rurais, da mentalidade tradicional e de manutenção do império colonial (TORGAL, 2009). Economicamente, as colônias não absorviam o comércio externo português, não havendo dependência econômica das colônias a Portugal, mas sim, a dependência de Portugal às colônias que, por sua vez, se apoiaria cada vez mais na guerra colonial (SECCO, 2004).

Durante o salazarismo, a combinação entre colonialismo e a resistência do regime ditatorial ao grande capital assumem a dimensão de um "bloqueio ideológico" da sociedade portuguesa (SANTOS, 1990, p. 33). Tal bloqueio somente poderia ser resolvido na associação da luta contra o salazarismo e da luta anti-colonial pelos movimentos de libertação nacional. A paralisia do Estado português refletiu um período de defasagem entre o Estado e a Sociedade Civil, mantendo a forma fascista de dominação assegurada por um pacto de classes em um contexto de lutas sociais agudas. $\mathrm{O}$ acirramento da contradição entre capital e trabalho, o aumento da força produtiva e do capital total, convivia sem alterações profundas nas estruturas sociais (LOUÇÃ, 2011). Notoriamente, a fragilização da dominação salazarista despontou a possibilidade de ações coletivas nos setores operários e sociais (ESTANQUE, 2000). O movimento estudantil, por sua vez, empreendeu sua participação em torno das questões referentes ao modelo de ensino e de liberdade de associação durante as "crises acadêmicas" de 1962 e de 1969 - a primeira ocorrida em Lisboa e a segunda em Coimbra - remetendo-se às políticas educacionais do regime salazarista.

A “crise de 1962" dispõe de atenção ao Decreto-lei nº 40.900/56, que estabelecia a proibição das liberdades associativas conquistadas anteriormente, colocando os órgãos estudantis subordinados ao Ministério da Educação, em uma situação de "asfixia" que resultaria em protestos (BEBIANO; ESTANQUE, 2007). A especificidade 
das lutas estudantis desse período, portanto, se dará no sentido reformista, pois busca a restauração das liberdades sem uma crítica profunda ao salazarismo, embora a proibição de eventos e encontros estudantis, a perseguição política às Associações Acadêmicas tenha gerado a acentuação das lutas sociais. Como muitos eventos de debate ao DL-40.900/56 e as condições das universidades, estavam sendo interrompidos pela Polícia Internacional e de Defesa do Estado (PIDE) e como muitos estudantes estavam sendo presos, seguiram-se vários "lutos acadêmicos" (não comparecimento nas aulas) na Universidade de Lisboa, mas também em Coimbra e Porto. A elaboração do DecretoLei 44.632, de 15 de outubro de 1962 (que revogava o DL-40.900/56), foi um aparente "ponto final" sobre esses primeiros ocorridos, pois mantinha a interferência do Estado sobre as organizações estudantis, aumentando a tutela sobre as Associações (CRUZEIRO, 1989).

Por isso, uma baixa contestatória se instaurou, causando uma sensação de derrota das reivindicações de 62, no que diz respeito à incapacidade de derrocada do regime salazarista e pela desmobilização subsequente (CAIADO, 1990). A mudança de estratégia, da combatividade à defensividade, pode ser referenciada em dois objetivos: a retomada da atividade tradicional de prestação de serviços das Associações e a ausência de interesses dos universitários para a mobilização. Com alguma movimentação retomada em 1965, começava a delinear-se a resistência estudantil contra o autoritarismo salazarista, em especial, por conta de declarações polêmicas do Ministro da Educação, Galvão Teles, que ameaçou de punição os estudantes caso houvesse distúrbios.

Com a saída de Salazar do Conselho de Ministros e a nomeação de Marcello Caetano para tal função, em setembro de 1968, pairou um clima otimista de mudança nos rumos políticos, a chamada Primavera Marcelista (BEBIANO, 2003). Caetano havia sido o antigo reitor da Universidade de Lisboa demitido na Crise de 1962 e era visto por uma 
atitude política mais liberalizante que a de Salazar e pela aproximação com a população, o que gerou uma expectativa de "descompressão" política do regime. Essa imagem foi reforçada pela permissão de regresso do exílio do líder socialista, Mário Soares, e do bispo do Porto, Antônio Ferreira Gomes, pela limitação de poderes da polícia e mudança da PIDE para Direção-Geral de Segurança (DGS) e por uma nova legislação para os sindicatos, cujos resultados não precisariam ser homologados pelo governo (CARDINA, 2008).

Por parte da oposição ao governo ditatorial, com a intensificação das guerras coloniais, a incorporação dos jovens e estudantes na guerra consolidava-se como medida punitiva àqueles que se manifestavam em oposição à guerra ou que eram militantes políticos (BEBIANO, 2003). Também, seguiram-se várias cisões internas ao Partido Comunista Português (PCP) desde 1965, como crítica ao imobilismo e ao alinhamento de seu comitê central com a URSS. A opção pela luta armada, pela clandestinidade dos militantes e aproximações com o maoísmo, conduziu a maioria das rupturas das correntes, ainda que estas fossem identificadas pelo comitê central a partir do individualismo e do radicalismo pequeno burguês (CARDINA, 2011; CUNHAL, 1971). Por isso, os rumos das lutas e as alianças que estavam sendo construídas pelo PCP no movimento estudantil eram colocadas em dúvida, agregando ainda uma paulatina perda de hegemonia no meio estudantil.

Nesse turbulento contexto, intensificam-se os conflitos e prisões de estudantes nas movimentações ligadas à suspensão do Decreto-Lei no 44.632 e à libertação de estudantes presos. A Associação Acadêmica de Coimbra (AAC), órgão de representação estudantil da Universidade de Coimbra, renovava-se politicamente com estudantes ligados ao Conselho de Repúblicas, cuja linha de atuação reivindicava a queda do regime salazarista, o fim da guerra colonial e a solidariedade com os conflitos internacionais. A partir de vários encontros informais, 
os estudantes conseguiram encaminhar reivindicações por maior participação democrática dos estudantes nas políticas universitárias, contra a intervenção salazarista e criticando a reforma universitária tecnocrática que se avizinhava.

O ponto alto da Crise de 69 ocorreu a partir de 17 de abril, na visita de uma comitiva do governo para a inauguração do Prédio das Matemáticas na Universidade de Coimbra. Os estudantes compareceram massivamente para manifestar, carregando cartazes pela democratização do ensino. Alguns dos dirigentes da AAC também entraram na sala da inauguração, ficando frente a frente com o Ministro da Educação, José Hermano Saraiva. No decorrer do evento, o então Presidente da Direção Geral da AAC, o estudante de Direito, Alberto Martins, se manifesta pedindo a palavra. Sua intervenção foi negada, delineando o final abrupto do discurso do Ministro e a urgente retirada da comitiva, deixando a sala para os estudantes, que discursaram contra tal atitude. Alberto Martins foi preso pela PIDE ainda naquela noite junto com outros estudantes, o que gerou movimentações pela cidade exigindo sua libertação. Sucedeu-se uma série de mobilizações dos estudantes, cujo objetivo era assegurar a oposição ao governo, acirrando ainda mais o diálogo com o Ministro da Educação, que decide fechar a Universidade de Coimbra e manter a data dos exames, ocasionando, em contrapartida, a suspensão dos festejos dos finalistas (Queima das Fitas). Com a tensão do luto acadêmico de cerca de quatro meses, as ruas da cidade passaram a ser patrulhadas por jipes policiais, criando um clima de terror, com sucessivos bloqueios da Guarda Nacional Republicana (GNR), da PIDE e da Polícia de Segurança Pública (PSP). Além disso, o governo não permitia que as informações referentes aos acontecimentos se propagassem nem comentou os fatos.

Analisando os dois eventos de crises acadêmicas, é importante perceber que há dois aspectos políticos distintos. Se na "crise de 1962" os estudantes adotam a postura reformista pela liberdade associativa, 
na "crise de 1969" observa-se a tendência para a democratização das estruturas socioeconômicas do Estado Novo (CARDINA, 2008, p. 119), assumindo um posicionamento mais progressista, de efetiva "intervenção estudantil" na política (BEBIANO; ESTANQUE, 2007, p. 36). A crise de 1969 almejou a construção de uma democracia de base como afronta ao autoritarismo, embora o período de maior repressão tenha sido posterior, em simultâneo com as mobilizações dos trabalhadores (ACCORNERO, 2009). Deve-se notar que, a partir de 1969 inicia-se, nas universidades, a discussão de um projeto de reforma universitária, cuja implementação se dará em 1971, com a Reforma Veiga Simão, de cunho tecnocrático, satisfazendo as elites desenvolvimentistas (SEDAS NUNES, 1970). A forma que os estudantes viam o autoritarismo das estruturas universitárias e de controle sobre a vida estudantil não era similar ao desejo liberalizante do governo de Caetano e, tampouco ignorava o problema colonial.

\section{Considerações Finais}

A partir das considerações apresentadas nos dois excertos anteriores é possível estabelecer uma breve análise comparativa através das dinâmicas estabelecidas. Destacam-se três aspectos: caráter das mobilizações, caráter das demandas e a violência ditatorial.

1) Sobre as mobilizações, pode-se aferir que enquanto no Brasil a centralidade das mobilizações foi liderada pela UNE, em Portugal a ausência da uma organização nacional fez com que as Associações Acadêmicas tivessem um papel preponderante. A presença de manifestações de rua no Brasil demandaram uma atuação mais engajada e com a participação de estudantes de vários lugares do país, e, por razão da estruturação nacional, após o fechamento da UNE foi muito difícil conseguir o fôlego anterior.

Nas mobilizações portuguesas há a restrição ao espaço local, mas culminou em ganhos políticos e de poder das Associações e, 
por mais que elas tenham sido fechadas como na crise de 1969, não houve a desestruturação do movimento estudantil. Dois fatores também podem ser considerados: mesmo com os intervalos entre as crises acadêmicas, por quase uma década, os estudantes ofereceram uma resistência ao autoritarismo salazarista; e, ademais da prática institucional das Associações, revela-se o quão atrelado ao controle do Estado era a universidade e o movimento estudantil, pois suas mobilizações evitam o confronto aberto com o regime salazarista diferentemente do que ocorreu no Brasil.

2) Sobre o caráter das demandas reivindicativas, se no caso brasileiro o mote inicial foi a reforma universitária, em Portugal essa reivindicação só ganhará corpo na "crise de 1969", pois anteriormente foi reivindicada a liberdade de organização. Quanto ao Brasil, não se poderia esquecer que a Lei Suplicy retirou a liberdade de representação da UNE em 1964, mas, em 1968, coloca-se a questão dos interesses da reforma universitária tecnicista e elitista. Pode-se aferir, em termos comparativos, que, por tratarem de conteúdos próximos a Reforma de 1968 (Brasil) e a Reforma Veiga Simão de 1971 (Portugal), versam sobre o mesmo espírito tecnicista, empresarial e modernizante.

3) Quanto à violência ditatorial, ela se dá de forma mais direta no Brasil mas existe de forma direta e simbólica em Portugal. A partir da morte de Edson Luiz a perseguição aos estudantes foi mais constante, resultando em grande quantidade de presos, mortos e desaparecidos e, sobretudo, nas sistemáticas perseguições aos militantes da esquerda. Em Portugal, a prisão de estudantes ocorre desde a crise de 1962, mas somente mais tarde, em 1972, irá resultar em uma morte. Isso significa que não é possível comparar qualitativamente os dois usos de violência. Para se estabelecer um breve paralelo, entende-se que o uso repressivo das forças nos dois contextos se dá por um diferencial: se no Brasil há um quadro de violência desvelada e direta, em Portugal, o regime salazarista recorre, sobretudo, à forma de violência simbólica (BOURDIEU, 1989), atacando os valores de status dos estudantes. 
Em Brasil e Portugal, as manifestações estudantis trouxeram um horizonte de expectativas positiva para aquele momento, no sentido de que os regimes ditatoriais poderiam ser derrotados, ao contrário de um certo espírito de derrota carregado no pós-1968. Por isso, a ausência revelada como presente nessa situação diz respeito a uma diferença entre o horizonte de expectativas e do espaço de experiências (KOSELLECK, 2006). Se, no Brasil, a expectativa de derrubada do regime ditatorial se deu com grande entusiasmo pelos estudantes e pela esquerda, a experiência de forte repressão não deixou que esse tenha sido um caminho fácil para a transição democrática. Em Portugal, as expectativas dos estudantes também eram grandes perante a derrocada do salazarismo e, apesar das experiências de violência direta e simbólica, a transição democrática iniciou-se anos depois, com o 25 de Abril. Em ambos, carrega-se uma "certa" herança crítica de 1968, a construção de uma democracia "imaginada" de baixo para cima, que permitisse a transposição da política do ambiente universitário para o âmbito nacional para a construção de uma nova cultura política: anti-sistêmica, pouco institucionalizada e autonomista.

\section{REFERÊNCIAS}

ACCORNERO, Guya. Efervescência estudantil: estudantes, ação contenciosa e processo político no final do Estado Novo (1956-1974). 2009. Tese (Doutorado em Ciências Sociais) - Universidade de Lisboa, Lisboa, 2009.

ALMADA, Pablo. A árvore de maio: resistência estudantil e sua atualidade (Brasil e Portugal). 2015. Tese. (Doutoramento em Democracia no Século XXI) - Faculdade de Economia, Universidade de Coimbra, Coimbra, 2015.

ARRIGHI, Giovanni; HOPKINS, Terence; WALLERSTEIN, Immanuel. Antisystemic movements. London: Verso, 1989.

BARKER, Colin. Revolutionary rehearsals. Chicago: Haymarket Books, 2008.

BEBIANO, Rui. O Poder da imaginação: juventude, rebeldia e resistência nos anos 60. Coimbra: Angelus Novus, 2003. 
BEBIANO, Rui. ESTANQUE, Elísio. Do activismo à indiferença: movimentos estudantis em Coimbra. Lisboa: ICS, 2007.

BOLTANSKI, Luc; CHIAPELLO, Ève. Le nouvelle espirit du capitalism. Paris: Gallimard, 1999.

BOREN, Mark E. Student resistance: a history of unruly subject. London: Routledge, 2001.

BOURDIEU, Pierre. O poder simbólico. Lisboa: Difel, 1989.

CAIADO, Nuno. Movimentos estudantis em Portugal: 1945-1980. Lisboa: IED, 1990.

CARDINA, Miguel. A tradição da contestação: resistência estudantil em Coimbra no Marcelismo. Coimbra: Angelus Novus, 2008.

CARDINA, Miguel. Margem de certa maneira: o maoismo em Portugal (1964-1974). Lisboa: Tinta da China, 2011.

CRUZEIRO, Celso. Coimbra, 1969: a crise acadêmica, o debate das idéias e a prática, ontem e hoje. Porto: Afrontamento, 1989.

CUNHAL, Álvaro. Radicalismo pequeno burguês de fachada socialista. Lisboa: Avante, 1971.

CHAUVEL. Louis. Le destin des générations: structure sociale et cohortes en France au XXe siècle. Paris: PUF, 2002.

ESTANQUE, Elísio. Entre a fábrica e a comunidade: subjectividades e práticas de classe no operariado do calçado. Porto: Afrontamento, 2000.

FERNANDES, Florestan. Universidade brasileira: reforma ou revolução. São Paulo: Alfa-Ômega, 1975.

FORACCHI, Marialice. 1968: el movimiento estudiantil en la sociedad brasileña. Revista Mexicana de Sociología, Ciudad de México, v. 31, n. 3, p. 609-620, 1969.

GORENDER, Jacob. Combate nas trevas: a esquerda brasileira: das ilusões perdidas à luta armada. São Paulo: Ática, 1987.

HABERMAS, Jürgen. Toward a rational society: student protest, science and politics. Boston: Beacon, 1971.

JAMESON, Fredric. Periodizando os anos 60. In: HOLLANDA, Heloisa Buarque (Org.). Pós-modernismo e política. Rio de Janeiro: Rocco, 1992.

KATSIAFICAS, Georgy. The imagination of the new left: a global analysis of 1968. Cambridge: South End, 1987. 
KOSELLECK, Reinhart. Futuro passado: contribuição à semântica dos tempos históricos. Rio de Janeiro: Contraponto, PUC, 2006.

LOUÇÃ, Francisco. Portugal agrilhoado: a economia cruel na era do FMI. Lisboa: Bertrand, 2011.

MARCUSE, Herbert. A ideologia da sociedade industrial: o homem unidimensional. Rio de Janeiro: Zahar, 1973.

MARCUSE, Herbert. The new left and the 1960s. Abingdon: Routledge, 2005.

MARINI, Rui Mauro. Dialética da dependência. Petrópolis: Vozes, 2000.

MARTINS FILHO, João Roberto. Movimento estudantil e ditadura militar (1964-1968). Campinas: Papirus, 1987.

MARWICK, Arthur. The sixties: cultural revolution in Britain, France, Italy, and the United States (1958-1974). Oxford: Oxford University, 1998.

PEREIRA, João Martins. Pensar Portugal, hoje. Lisboa: Dom Quixote, 1979.

POERNER, José. O poder jovem: história da participação política dos estudantes brasileiros. Rio de Janeiro: Civilização Brasileira, 2008.

REIS FILHO, Daniel Aarão. A revolução faltou ao encontro: os comunistas no Brasil. São Paulo: CNPq/Brasiliense, 1990.

RIDENTI, Marcelo. O Fantasma da revolução brasileira. São Paulo: UNESP, 2010.

SANTOS, Boaventura S. O Estado e a sociedade em Portugal (1974-1988). Porto: Afrontamento, 1990.

SANTOS, Boaventura S. A gramática do tempo: para uma nova cultura política. Porto: Afrontamento, 2006.

SECCO, Lincoln. A revolução dos cravos e a crise do império colonial português: economias, espaços e tomadas de consciência. São Paulo: Alameda, 2004.

SEDAS NUNES, Adérito. O problema político da universidade. Lisboa: Dom Quixote, 1970.

STEPHENS, Julie. Anti-disciplinary protest: sixties radicalism and postmodernism. Cambridge: Cambridge University, 1998.

TORGAL, Luis Reis. Estado novo, Estados novos: ensaios de história política e cultural. Coimbra: Universidade de Coimbra, 2009. v. 1.

TOURAINE, Alain. A sociedade post-industrial. Lisboa: Moraes, 1971.

VALLE, Maria Ribeiro. 1968: o diálogo é a violência. Campinas: Unicamp, 2008. 